\title{
Investigation of Pre- and Post-Swelling Behavior of Elastomeric Material
}

\author{
M Akhtar*a, Md Velden ${ }^{\mathrm{b}}$ and SSA Al-Houqanic \\ ${ }^{*}$ Mechanical Engineering Department, NED University of Engineering and Technology, Karachi, Pakistan \\ ${ }^{b}$ Senior Well Engineer Concept and Design, Shell Oil, Seria, Brunei \\ ${ }^{c}$ Well Engineering Directorate, Petroleum Development Oman (PDO), Muscat, Oman
}

Received 5 January 2012 ; accepted 29 November 2012

\begin{abstract}
In the last ten years, a new type of modern polymer, known as swelling elastomer, has been used extensively as a sealing element in the oil and gas industry. These elastomers have been instrumental in various new applications such as water shut off, zonal isolation, and sidetracking. Though swell packers can significantly reduce costs and increase productivity, their failure can lead to serious losses. The integrity and reliability of swelling elastomer seals under different field conditions is a major concern. The investigation of changes in material behavior over a specified swelling period is a necessary first step for performance evaluation of elastomer seals. The current study is based on experimental analysis of changes in geometric and mechanical behavior (hardness, tensile, compressive, bulk) of an elastomeric material due to swelling. Tests were carried out before and after various stages of swelling. Specimens were placed in saline water $\left(0.6 \%\right.$ and $12 \%$ concentrations) at a temperature of $50^{\circ} \mathrm{C}$, with the total swelling period being one month. Swelling, hardness, compression, and bulk tests were conducted using disc samples, while ring samples were used for tensile experiments. A small test rig was designed and constructed for determination of bulk modulus. Stress-strain curves under tension and compression, and pressure volumetric-strain curves were obtained for specimens subjected to different swelling periods. Due to the fast-swell nature of the elastomer, there were sharp changes in mechanical properties within the first few days of swelling for both salinities. Elastic modulus derived from tensile and compressive tests showed a $90 \%$ decrease in the first few days. Bulk modulus showed fluctuation in its variation with an increasing swelling period. There was a small effect of salinity only during the first 5 or 6 days.
\end{abstract}

Keywords: Swelling elastomer, Swelling behavior, Tensile testing, Compression testing, Bulk testing

$$
\begin{aligned}
& \text { التحقيق في سلوك مواد اللدائن قبل وبعد التورم } \\
& \text { معاذ اختر "* ، مارك د فيلدن بـ و سعيدع س الحوقانيج }
\end{aligned}
$$

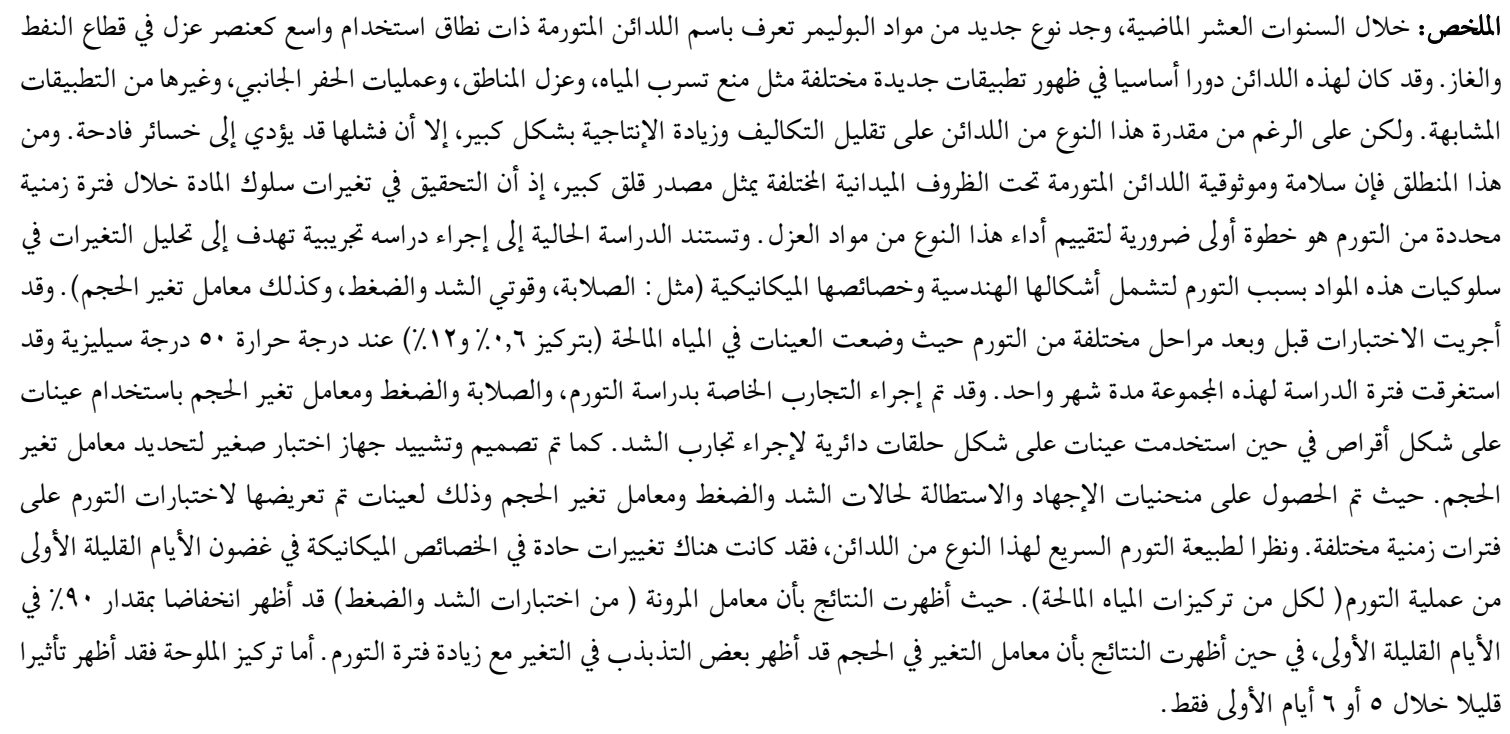

المفردات المفتاحية: اللدائن المتورمة، سلوك التورم، اختبار الشد، اختبار الضغط، اختبار معامل تغير الحجم

*Correspondng author's e-mail: maaz@neduet.edu.pk 


\section{Introduction}

Elastomers are rubber-like materials made from synthetic polymers. Swelling elastomers exhibit a dynamic change in volume and thickness when exposed to a swelling medium (water or oil). Swellable elastomer seals and packers consist of swelling elastomer sections bonded to tubulars. Production from many oil and gas fields drastically decreases due to problems such as formation damage and water incursion. Many mature wells have been abandoned after serious production declines, as the difficulties and cost of rework are significant. Advanced polymer applications known as swelling elastomer packers (SEPs) have successfully put many abandoned wells back into production, through strategies such as workovers, sidetracks, and redrills (Al-Saiid 2007; Al-Douseri 2010). Swelling elastomer sections can be deployed to segment horizontal wells, thereby shutting off unwanted water and gas, and can thus increase recovery from mature reservoirs (Tejas 2009; Al-Mahrooqi 2007). Successful applications of swelling elastomers include cementless completions (Rogers 2008; Nylund 2010), well completion together with cement jobs (Cooper 2008), zonal isolation in open-hole completion of foam-drilled horizontal wells (Allison 2009), etc.

Success of an elastomer-based field application depends on various factors, including selection of swell packers that are appropriate for a given set of field conditions; improvement of sealing design, and assessment of seal integrity. None of these tasks can be carried out without a reasonably accurate knowledge of material response of the elastomer under given conditions and at various stages of swelling. Kubena et al. (1991) investigated how different drilling fluids affect the performance characteristics of certain types of elastomers used in drilling equipment. Al-Yami (2008a; 2008b) studied the resistance of water-swelling and oil-swelling elastomer seals to differential pressures at a given temperature. Ertekin and Sridhar (2009) reviewed the performance and compatibility of some elastomeric materials to gasoline mixtures containing various concentrations of hydrocarbons. Material response (volume and thickness swelling, compression set, tensile set, etc.) of an ethylene-propylene diene monomer (EPDM)-type rubber water-swelling elastomer was studied by Qamar (2009; 2012a and Pervez 2012). Akhtar et al. (2012) compared different material models that can be used for simulation studies of swelling elastomers under tensile loading. Qamar et al. (2012b) investigated the mechanical and structural behavior of a swelling elastomer under compressive and bulk loading. Results summarized in this paper are based on a study conducted for material testing and characterization of a high-performance candidate elastomer (water-swelling) used in swell packers in petroleum drilling operations.

\section{Experimental Work}

\subsection{Preparation of Samples}

A die-and-punch set was used to cut disc samples in line with American Society for Testing and Materials (ASTM) D575 test standards: 28 millimeters in diameter and with a 12.5 millimeter thickness. These disc samples were used for swelling, compression, and bulk tests. Ring samples were cut in line with ASTM D412 test standards: an outside diameter of 19 millimeters, an inside diameter of 16 millimeters, and a thickness of 6 millimeters. These ring specimens were used for tensile tests. The actual identification number and commercial name of the swelling elastomer material has to be withheld for reasons of confidentiality.

\subsection{Experiment Details}

The objective of the current study is to investigate changes that occur in elastomers geometrically and mechanically due to swelling in a water-swelling elastomer used as a sealing element in oil drilling applications. Test conditions represented actual well conditions in many regional oil wells: saline water of $0.6 \%$ and $12 \%$ concentration and a test temperature of $50^{\circ} \mathrm{C}$. Readings were taken before swelling, and after $1,2,4,7,16,23$, and 30 days of swelling. Samples were placed in sealable glass jars containing a proper swelling medium and identified by mnemonic code names. Jars were placed inside servo-controlled ovens maintained at a temperature of $50^{\circ} \mathrm{C}$ throughout the 30-day test period.

\subsection{Swelling Medium}

For the testing of the water-swelling elastomer, distilled water was first processed in large quantities and stored. Saline solutions of $0.6 \%$ (6000 ppm) and $12 \%$ $(120,000 \mathrm{ppm})$ concentrations were prepared in enough quantity to last for the one-month testing, with a change of brine in each jar after every reading. For instance, a $12 \%$ solution was prepared by using a digital balance to measure 120 grams of salt, and dissolving it in one liter of distilled water.

\subsection{Types of Experiments}

Mechanical response was determined through three different sets of experiments: tensile tests for Young's modulus $(E)$, compression tests for Young's 

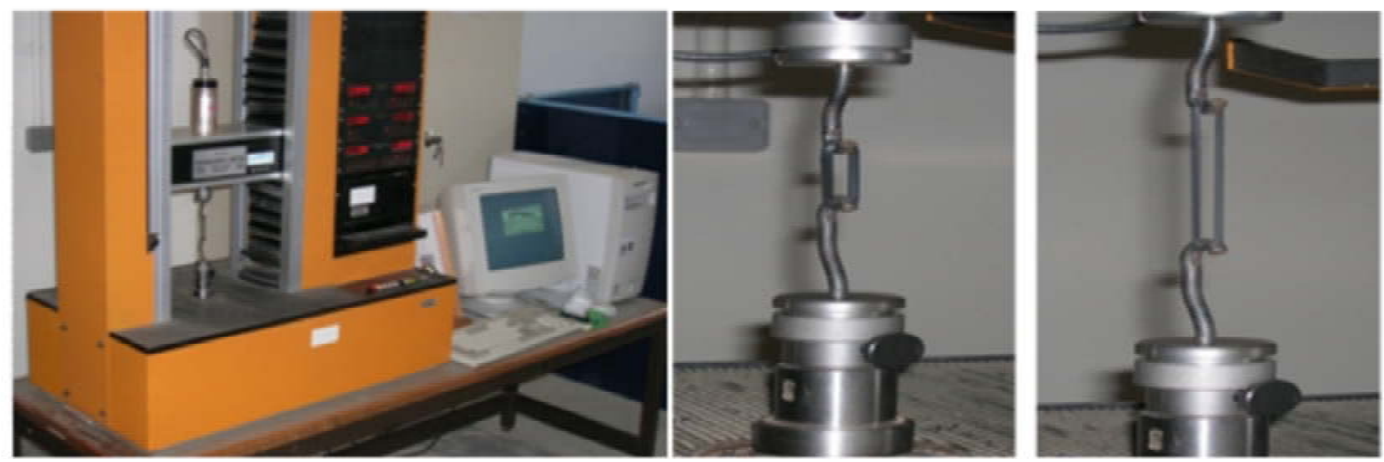

Figure 1. Tensile test set-up with specimens at different stags of testing
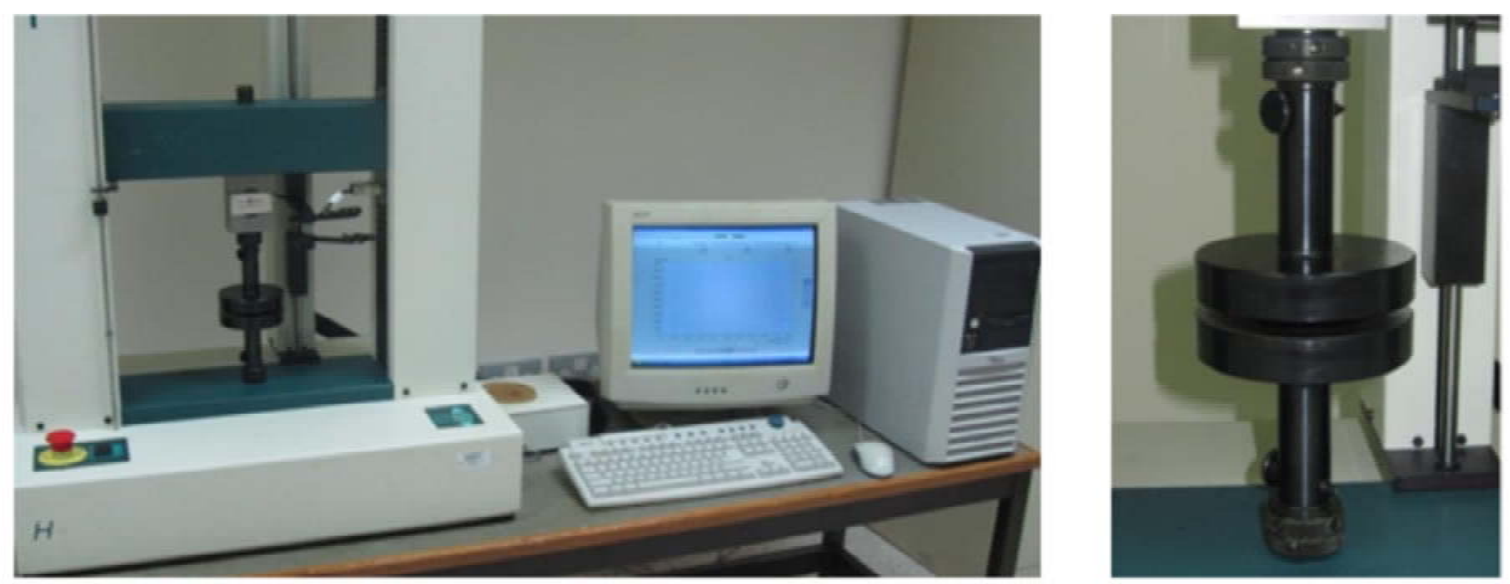

Figure 2. Compression test set-up

modulus (E), and bulk tests for bulk modulus $(K)$ along with swelling behavior. Mechanical tests were carried out before swelling and after different stages of swelling. Total swelling time was one month. All reported values are an average of readings from three samples.

\section{Swelling Behavior}

Disc samples were tested for volume, thickness, density/mass, and hardness changes. After measurement, discs were put back into their respective solutions. Volume measurements were done by a graduated beaker-cylinder arrangement that was specially developed in-house. Measurements were then based on the displacement method. Thickness measurements were carried out using digital Vernier calipers. Hardness readings were taken using a scale-A durometer.

\section{Tensile Testing}

The width, thickness, and flattened length of all samples before and after swelling were recorded prior to conducting the tensile test to be used later for stress and strain measurements. Specially fabricated hook- type fixtures (in accordance with ASTM D412) were used to grip the ring samples (Fig. 1). A small pre-tension was applied on each sample to get the flattened length. A loading rate of $500 \mathrm{~mm} / \mathrm{min}$ was used until the sample ruptured. Force-elongation and stressstrain readings were automatically recorded by the machine.

\section{Compression Testing}

The ASTM standard test method (ASTM D575) was followed for compression testing. A universal testing machine with a $50 \mathrm{kN}$ load cell was used in the compression mode (Fig. 2). The compressive load was applied at a rate of $12 \mathrm{~mm} /$ minute until the specimen thickness became $10 \mathrm{~mm}$. Force-deformation data were converted into stress-strain values for the plotting of graphs.

\section{Bulk Testing}

No test standard is available for bulk experiments of rubbers and elastomers. A small test rig was designed and fabricated to be used for bulk experiments on the universal testing machine (Fig. 3). Under compressive loading, the specimen was restricted to 

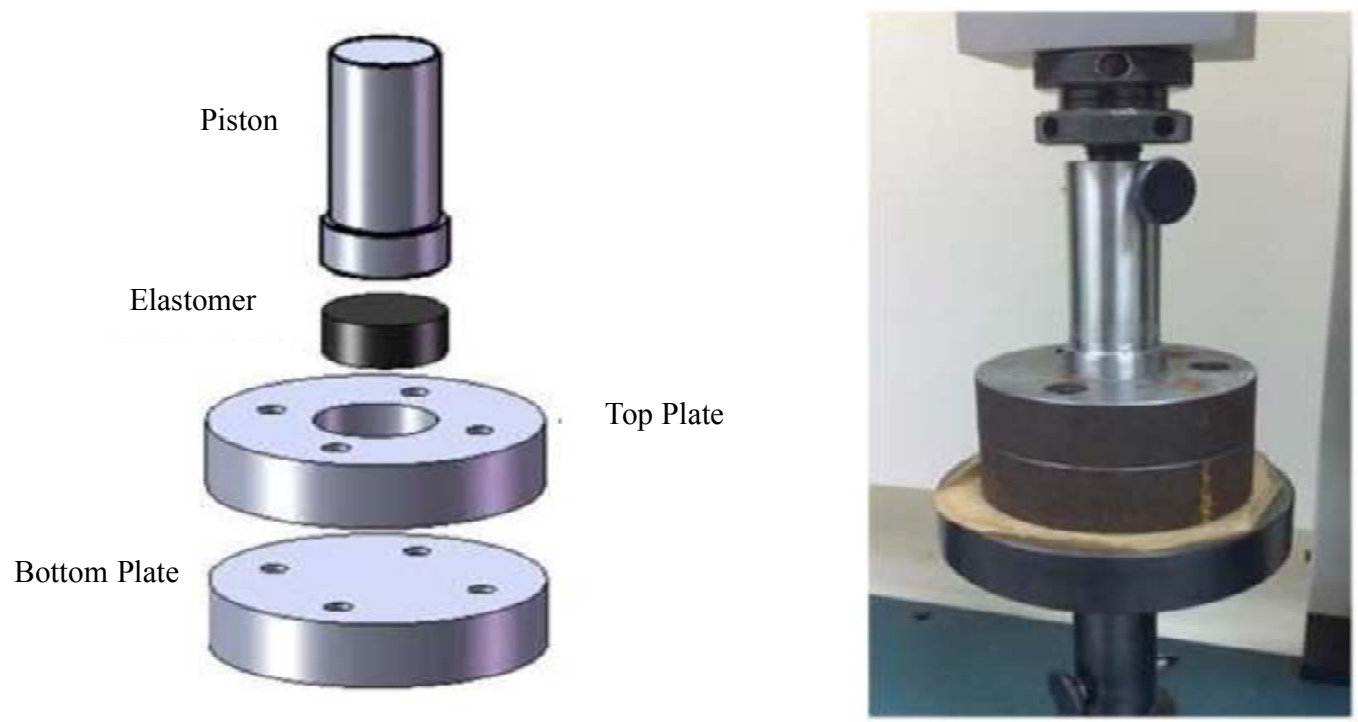

Figure 3. Test rig for bulk experiments, designed and fabricated in-house

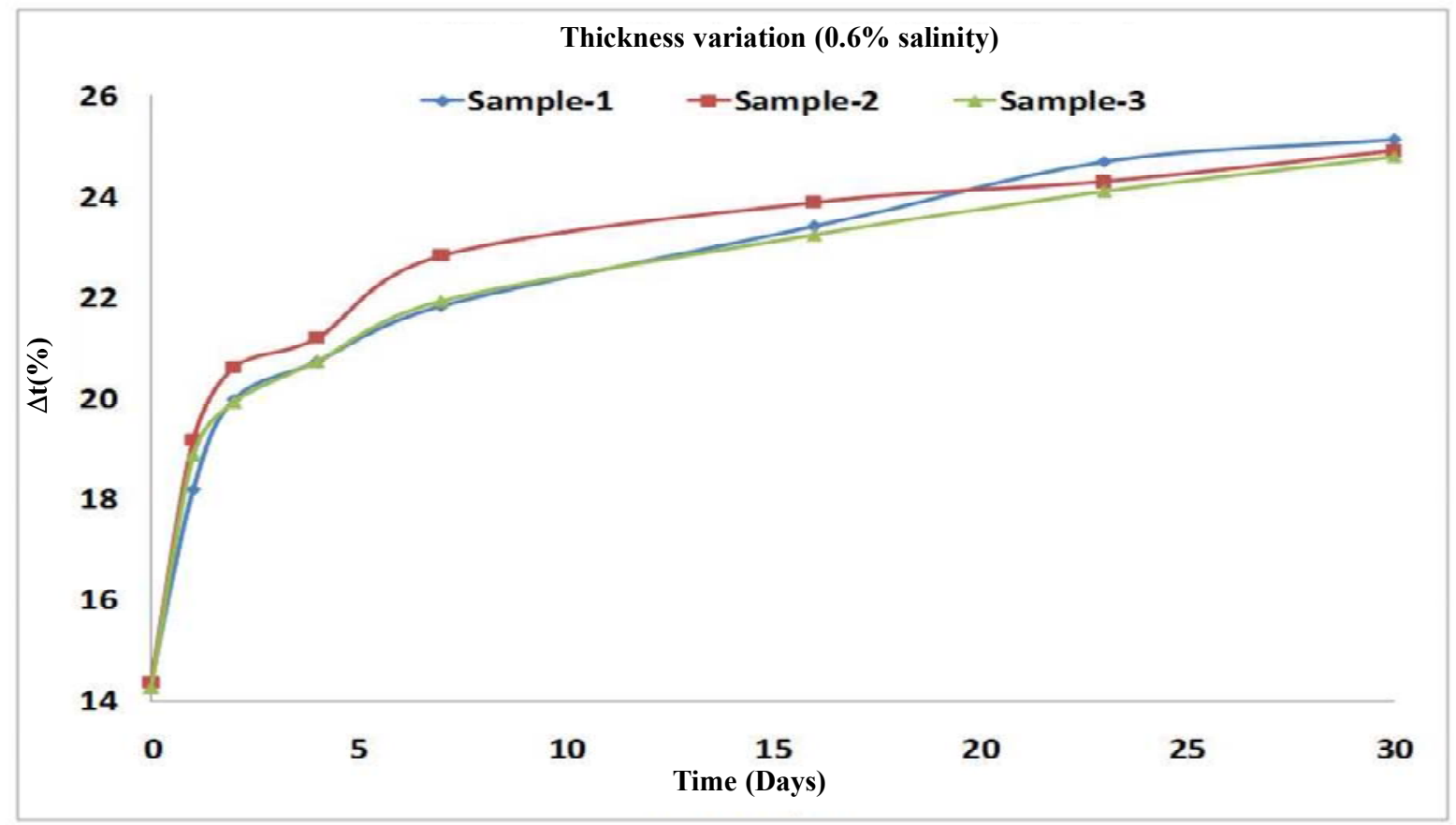

Figure 4. A three-sample thickness variation graph after one month of swelling at $0.6 \%$ salinity

move only in the axial direction, allowing no radial expansion. To be compatible with compression tests, the load was applied at the rate of $12 \mathrm{~mm} / \mathrm{min}$ until the specimen failed. Force-deformation results were used to produce graphs showing the variation of pressure against volumetric strain.

\section{Results and Discussion}

\subsection{Swelling Experiments}

These experiments recorded the changes in volume, thickness, density, and hardness in the elastomer samples against the number of days of swelling. One 3-sample swelling graph detailing thickness variation is shown in Fig. 4 as an example. The swelling of disc samples, which were free to swell in all directions, was done to provide a base for comparison. Volume swelling values are also given as a reference. For practical applications, thickness change is the actual parameter of interest as it affects the quality of sealing in petroleum related applications.

\section{Volume Change}

Figure 5 shows the change in volume of disc samples against days of swelling in $6000 \mathrm{ppm}(0.6 \%)$ and 120,000 ppm (12\%) brine solutions held at room tem- 

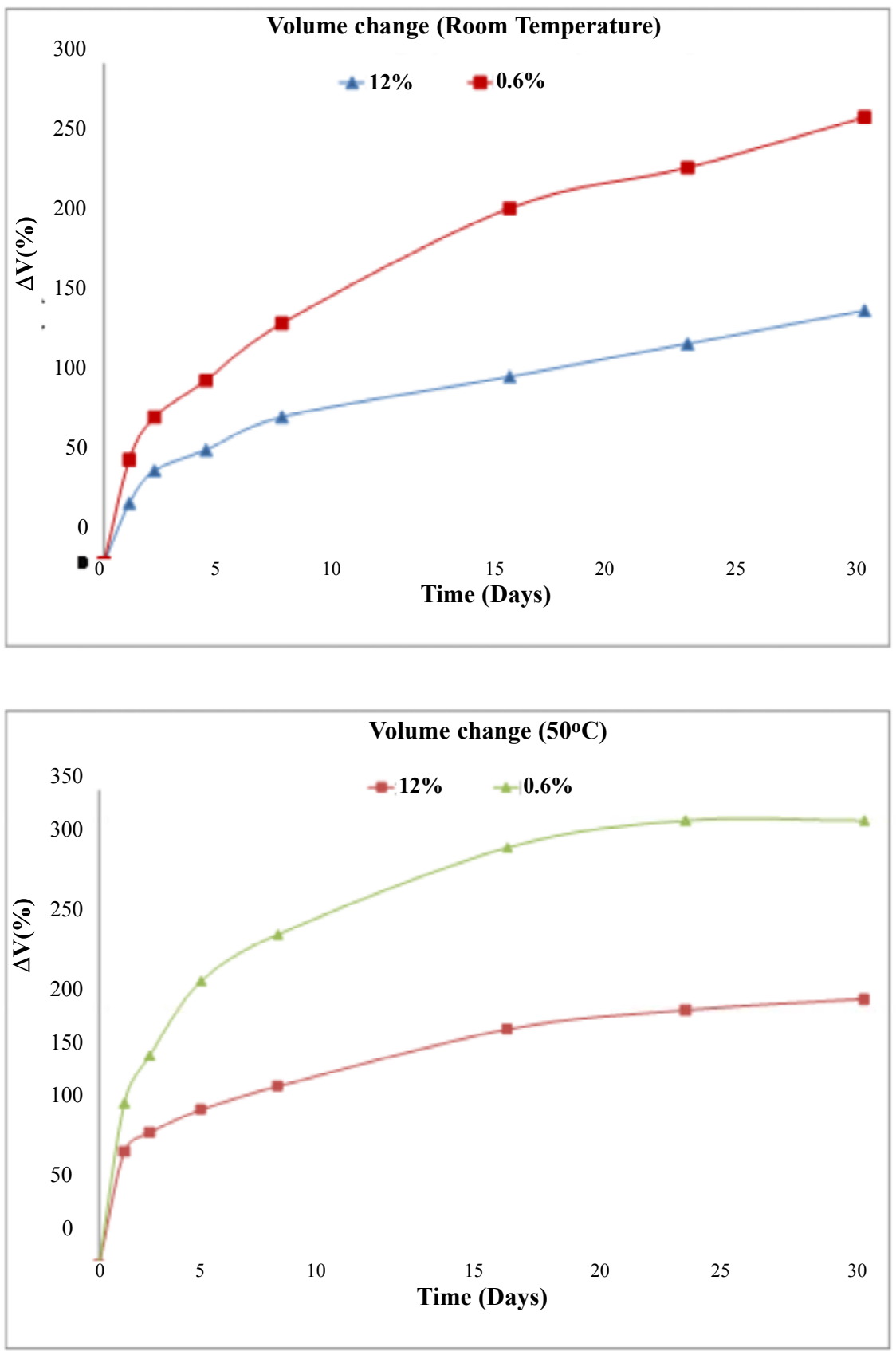

Figure 5. Changes in volume after one month of swelling at $0.6 \%$ and $12 \%$ salinity, held both at room temperature and $50^{\circ} \mathrm{C}$

perature and at $50^{\circ} \mathrm{C}$. The elastomer was a fast-swell type, so the increase in volume was very fast in the beginning, which could be observed in the first five days, reaching almost one-third of total volume increase. A gradual increase was noted for the remaining period. As observed in earlier studies, the swelling in the lower-concentration salt-solution was higher than in higher-concentration brine. Also, a higher volume of swelling was observed in samples kept at higher temperature, as was expected.

\section{Thickness Change}

Figure 6 shows thickness change in disc samples against swelling time in $0.6 \%$ and $12 \%$ salt solutions held at room temperature and at a temperature of $50^{\circ} \mathrm{C}$. The fast- swelling nature of elastomers resulted in a higher thickness increase in the beginning and a slower increase later on. Again, as expected, thickness swelling was higher for lower salt concentration and at higher temperatures.

\section{Hardness Change}

Hardness kept on decreasing as elastomers swelled more. Figure 7 summarizes the change in hardness as samples swelled in $0.6 \%$ and $12 \%$ salt solutions, at room temperature, and at $50^{\circ} \mathrm{C}$. It is interesting to 

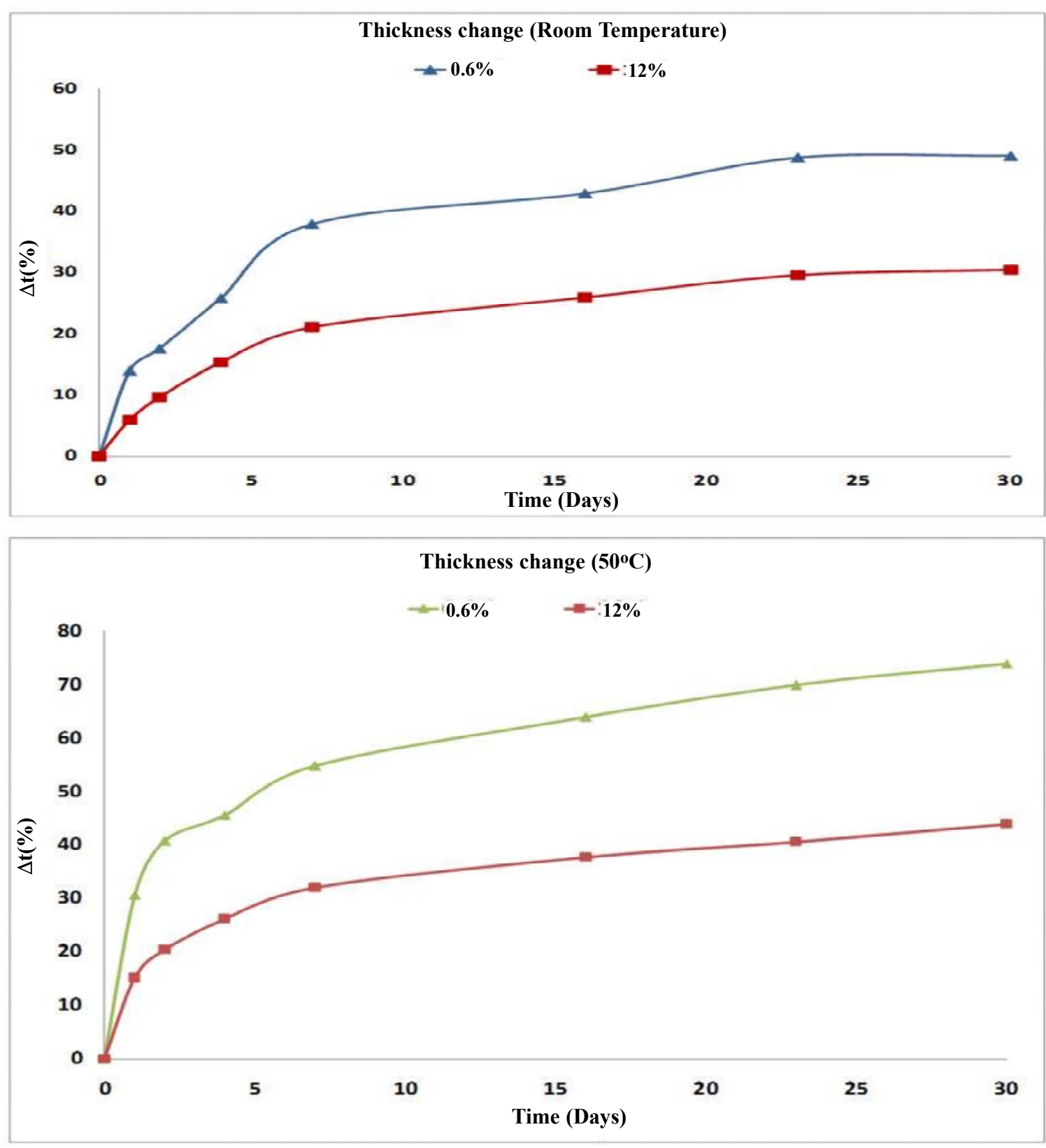

Figure 6. Thickness variation for a one-month swelling period with the solution held at $0.6 \%$ and $12 \%$ salinity at both room temperature and $50^{\circ} \mathrm{C}$

observe that within the first week of swelling, hardness drastically dropped and then remained almost constant. The hardness of the original elastomer samples (before swelling) on the Shore-A scale was around 62 . For low salinity at room temperature, hardness dropped to 12, and for the higher temperature it dropped to 7 in the first week. Similarly for higher salinity, at room temperature it dropped to a value of around 16 , and at $50^{\circ} \mathrm{C}$ dropped to around 10 .

\section{Density Change}

Density dropped considerably in the first few days for both salinities and temperatures, as can be seen in
Fig. 8. With more swelling, it increased a little before gradually dropping down to almost the same value as at the end of the first week. Due to two-way water and salt transport during swelling of these elastomers, both volume and mass changed, but at different rates; thus, the slightly zigzag pattern of density variation was observed.

\subsection{Mechanical Testing}

Three-sample stress-strain graphs for one case of tension ( $0.6 \%$ salinity and one day of swelling) and one case of compression (12\% salinity and 4 days of swelling) are shown in Figs. 9 and 10. It is recom- 

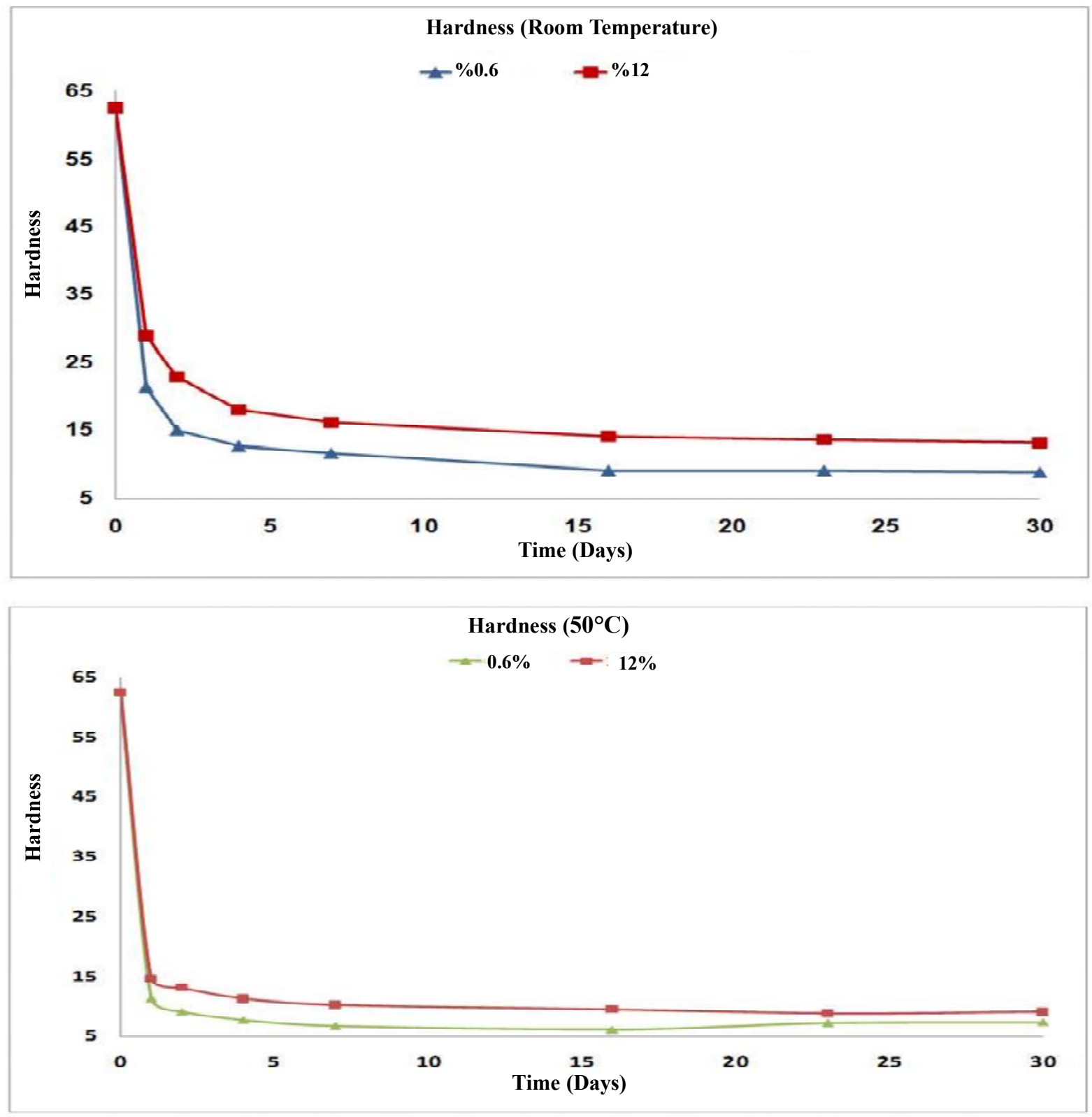

Figure 7. Change in hardness over a one-month swelling period at $0.6 \%$ and $12 \%$ salinity with solution held both at room temperature and $50^{\circ} \mathrm{C}$

mended that only the initial $10 \%$ data from a stressstrain curve should be used to determine Young's modulus for elastomers (Gent 2012), which was the approach followed in this paper. Figure 11 shows a sample of a linear curve fitting for the tension test. A 3-sample graph for bulk testing is shown in Fig. 12. Fitting a straight line to the linear portion of the bulk test graph yields the bulk modulus of the elastomer (Fig. 13). A goodness of fit of more than $99 \%$ in determination of $\mathrm{E}$ and $\mathrm{K}$ values is encouraging.

\section{Tensile Experiment}

As was expected, the stress-strain behavior of the elastomer under tension was non-linear (Fig. 9). With a higher amount of swelling, the elastomer tends to become linear. A comparison of stress-strain behavior for zero, 1, 7 and 30 days of swelling is shown in Fig. 14. Interestingly, after the first few days of swelling, stress-strain curves under tension were very close to each other. Also, the maximum strain under tension $(350 \%)$ was much higher than in compression $(80 \%)$. The reason for these two observations lies in the geometry of test samples. A tension test was done using ring samples in a very small area of the crosssection, while a compression test used disc specimens in a much larger cross-section.

\section{Compression Experiment}

A comparison between stress-strain behavior before swelling and after 1, 7 and 30 days of swelling is 
M Akhtar, Md Velden and SSA Al-Houqani
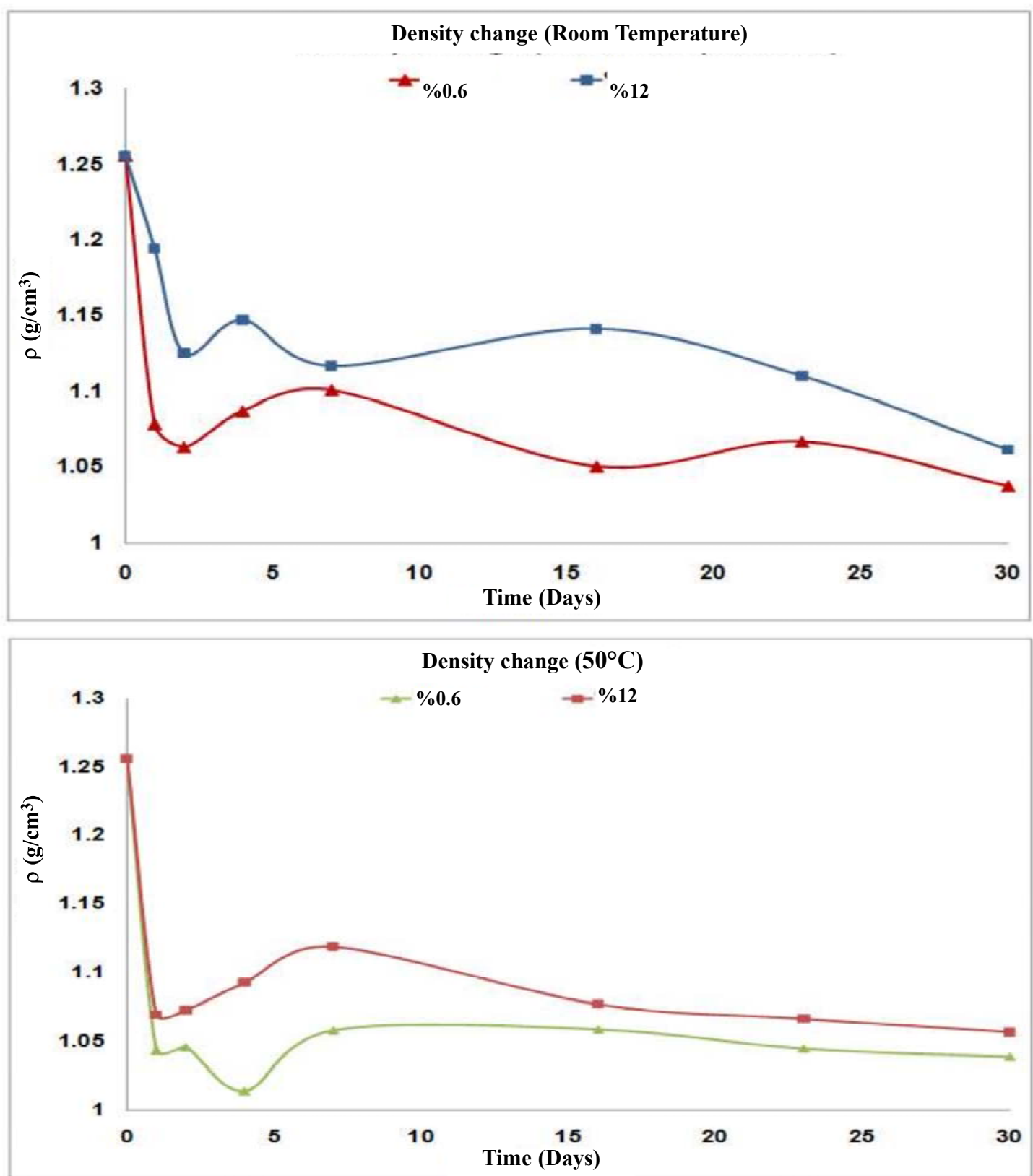

Figure 8. Density variation for a one-month swelling period at $0.6 \%$ and $12 \%$ salinity with solutions held at room temperature or $50^{\circ} \mathrm{C}$

shown in Fig. 15. There was a sharp decrease in compressive stress after one day of swelling. After 7 days of swelling, the drop in compressive stress was much lower. Upon further swelling, there was almost no change in stress values. Figure 16 compares stressstrain patterns between the two salinities $(0.6 \%$ and $12 \%$ ) after one day and 30 days of swelling. As expected, stress values were higher for $12 \%$ salinity as compared to $0.6 \%$, as lower salinities result in higher swelling (softer elastomer), thereby yielding lower stress values (Qamar 2009). At the end of the onemonth swelling period, swelling for both salt concentrations became almost the same; this gives nearly the same fracture loads.

\section{Bulk Experiment}

A change of pressure against volumetric strain is plotted in Fig. 17 for one and 30 days of swelling. Obviously, strains after higher swelling (30 days) were much larger. With more swelling, the elastomers became softer, yielding large strains at small loads, resulting in the trend shown in Fig. 17 (Qamar 2012).

\section{Variation of Elastic Modulus}

The variation of the elastic modulus under tension is shown in Fig. 18. The E-value decreased by more than $90 \%$ in only a few days; after that it remained almost unchanged. In the industry, this elastomer is called a fast-swell type; it swells at a rapid rate in the 


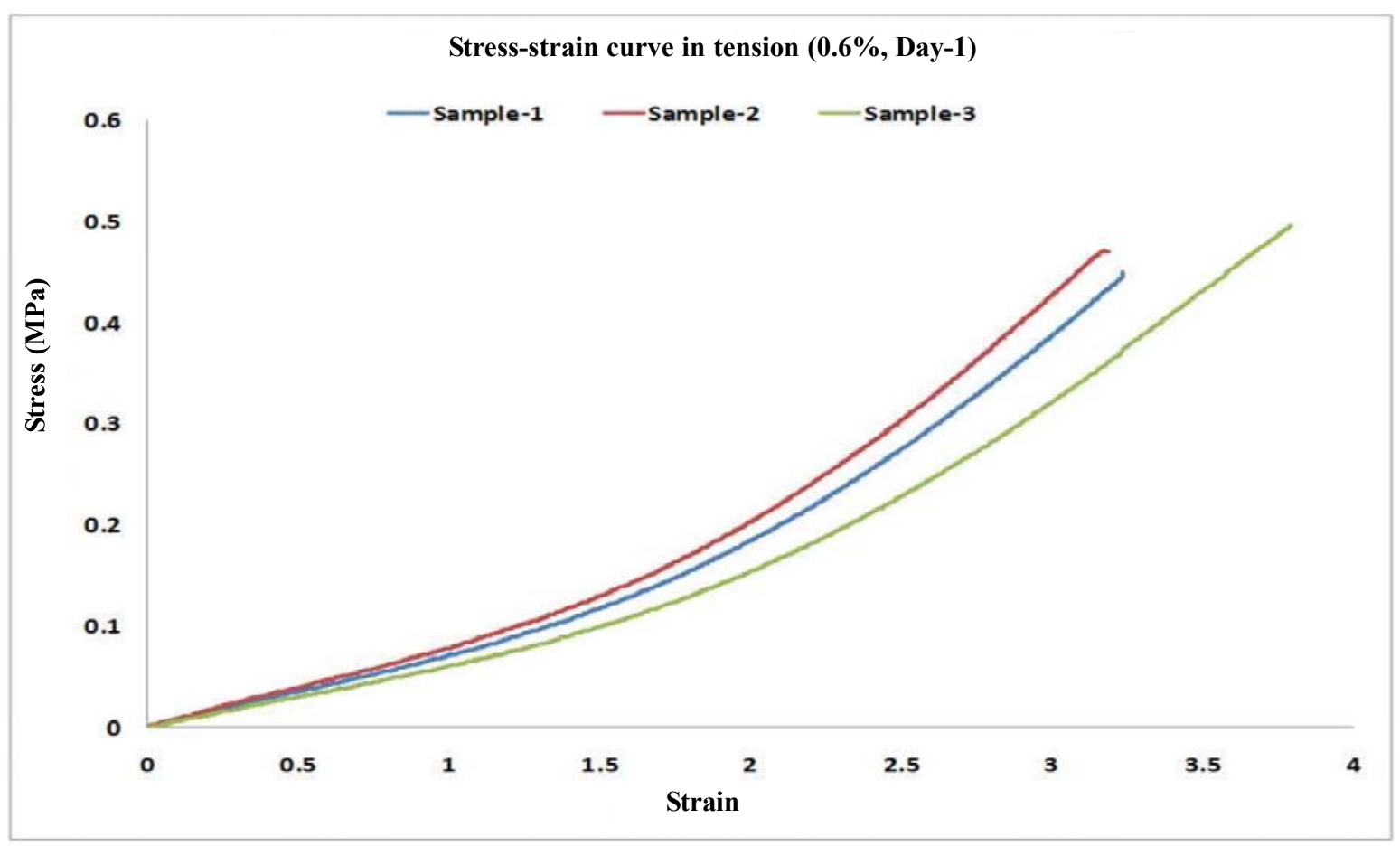

Figure 9. Three-sample stress-strain curve under tension at $0.6 \%$ salinity after one day of swelling

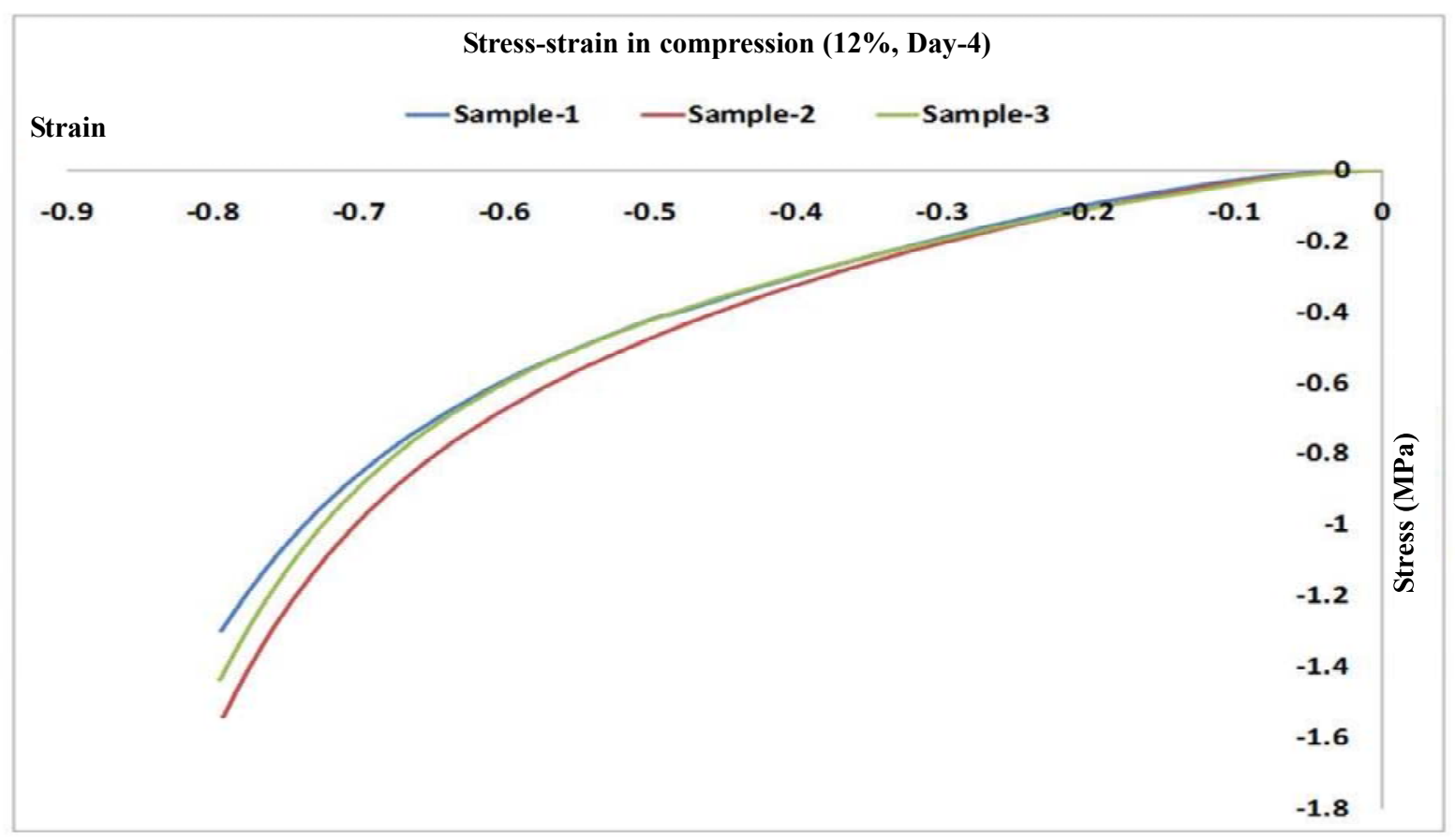

Figure 10. Three-sample stress-strain curve under compression at $12 \%$ salinity after 4 days of swelling

first few days, then swells more slowly. This characteristic guarantees good sealing in the first three to four days, allowing the oil/gas rig to go into production earlier than if the elastomer were a slow-swell type.

The slight fluctuation during the first 2-3 days of swelling is due to the nature of the swelling process.
We know that salt is one component of swelling elastomers. When elastomer samples are put in brine, some salt goes into the elastomer due to water absorption. On the other hand, some salt breaks out of the elastomer and goes into the salt solution. This two-way (but unequal) salt movement means that swelling does not increase consistently but may stop or even 


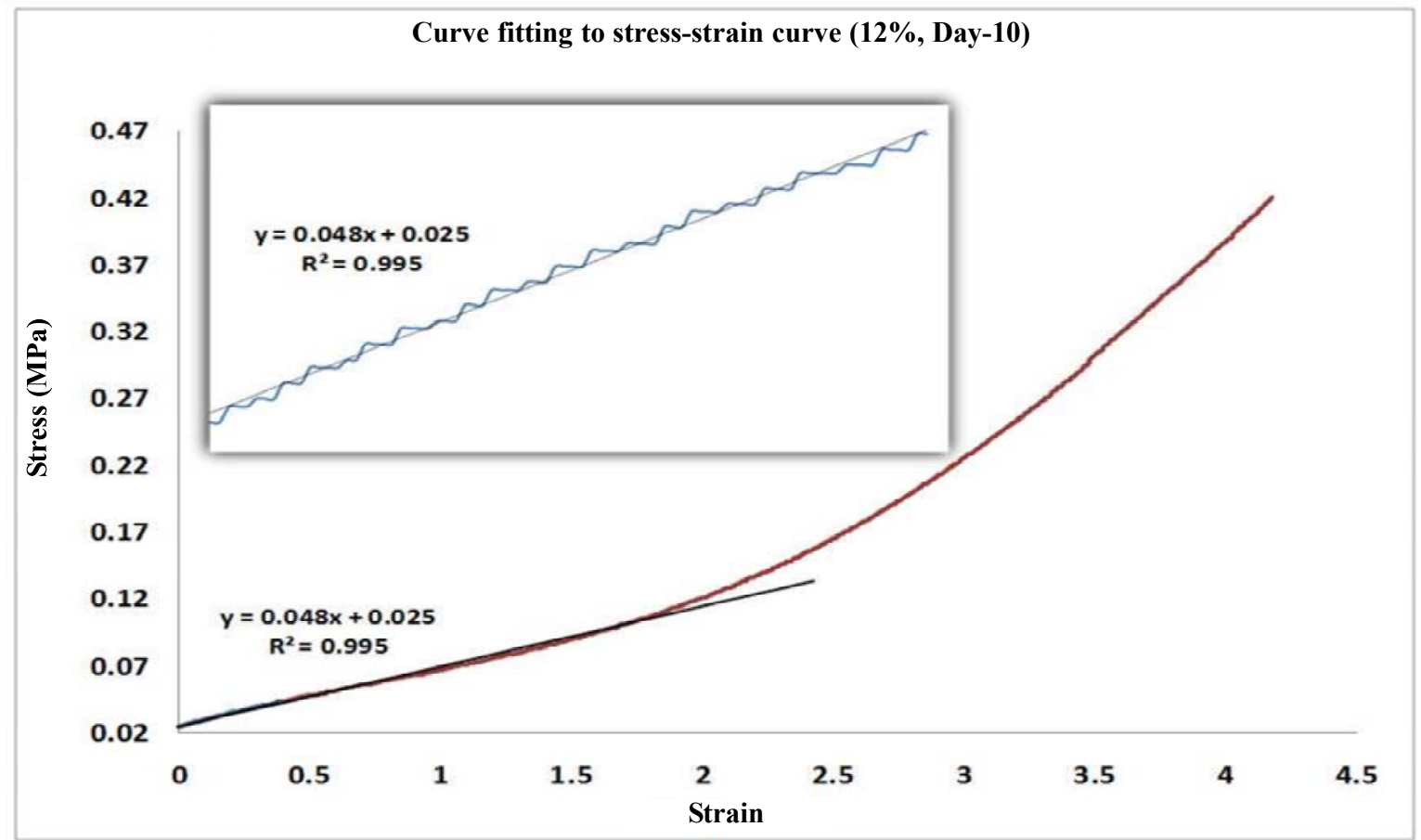

Figure 11. Linear fit to stress-strain curve under tension at $12 \%$ salinity after 10 days of swelling

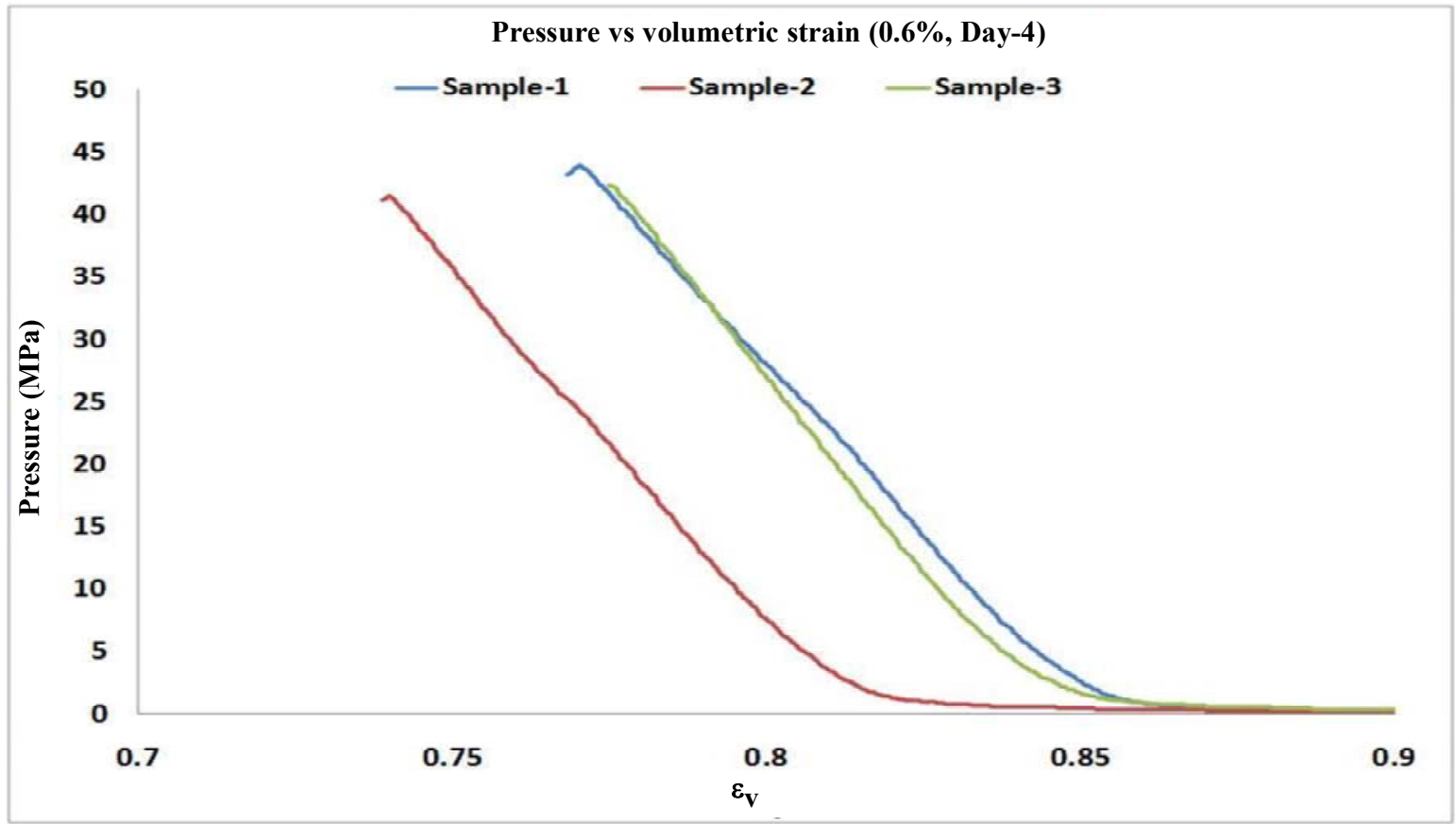

Figure 12. Three-sample pressure-volumetric strain curve at $0.6 \%$ salinity after 4 days of swelling

decrease a little before increasing again. In addition to this, the breaking and re-forming of cross-link chains due to two-way salt movement in these elastomers can also cause increasing-decreasing swelling patterns.

Variation of Young's modulus under compression is shown in Fig. 19. It decreases sharply in the first few days and then becomes almost constant. This is due to the reasons already explained above. A compar- ison of Figs. 18 and 19 shows that the behavior of swellable elastomers is considerably different under tension and compression; E-values are much higher under compression than under tension. Under compression, elastomers become stiffer and stronger (a general trend for polymers); thus, the higher modulus values. This is beneficial in the petroleum industry as swellable elastomers are generally used as seals, and 


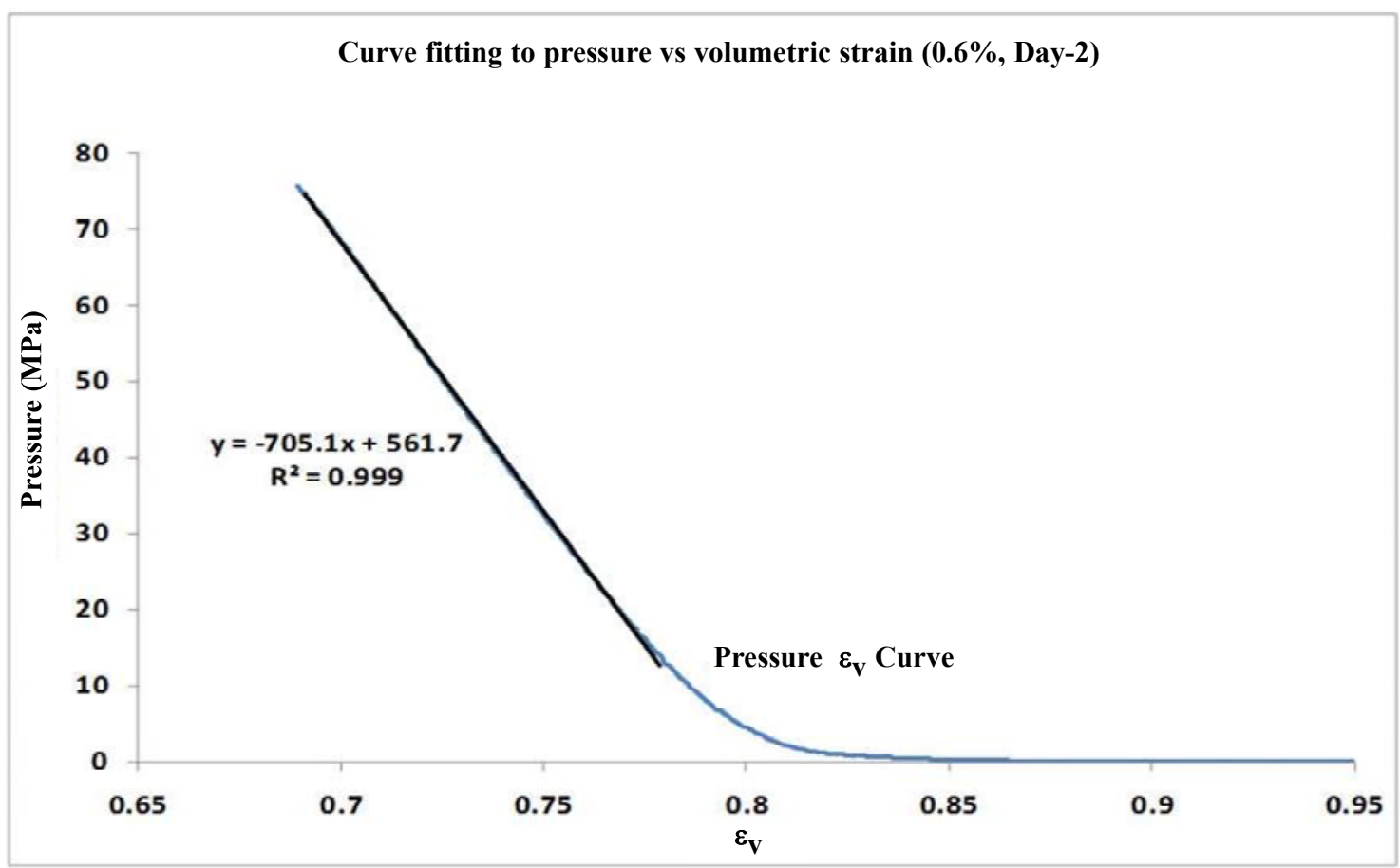

Figure 13. Linear fit to pressure-volumetric strain curve at $0.6 \%$ salinity after 2 days of swelling

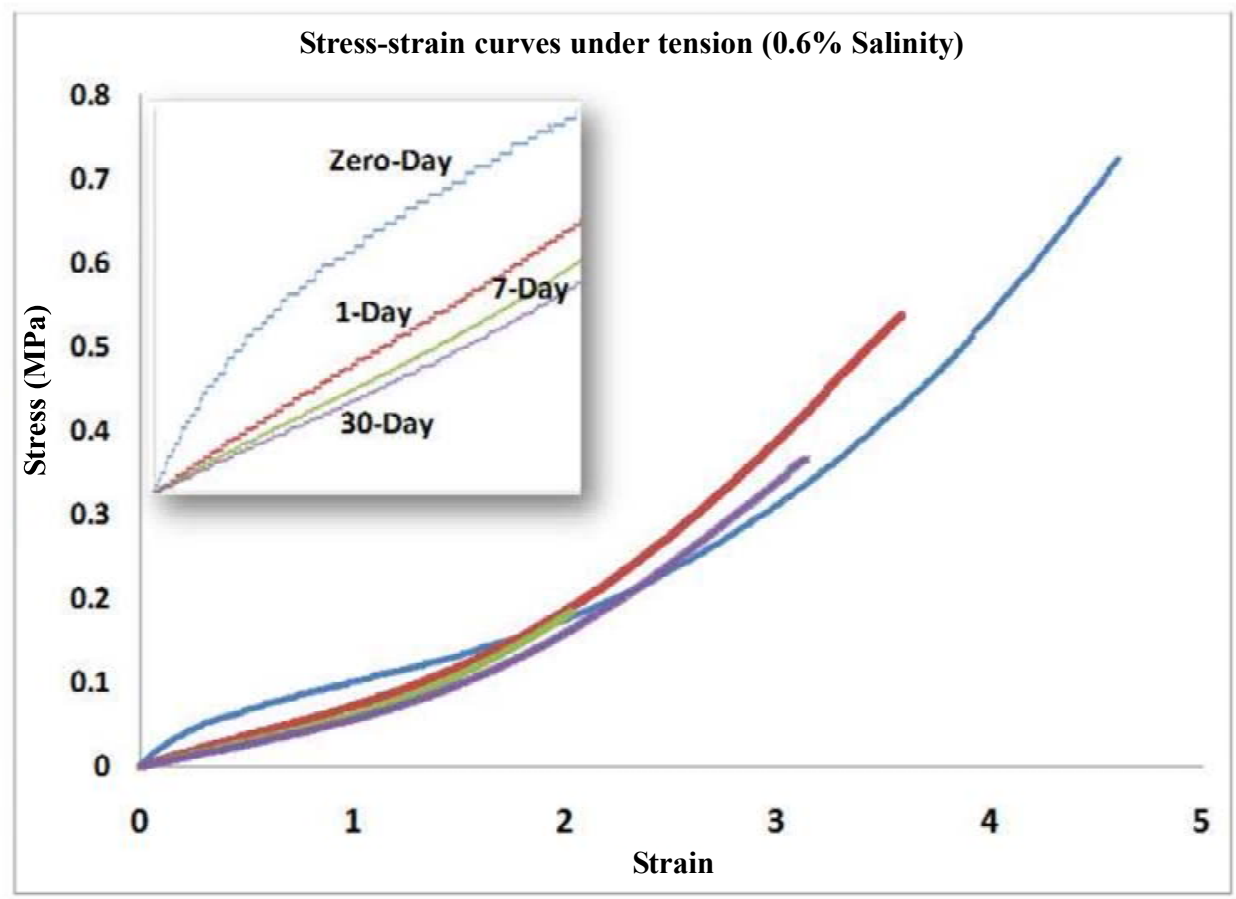

Figure 14. Stress-strain behavior under tension at $0.6 \%$ salinity after various swelling periods (Zero, One, 7 , and 30 days

seals are mostly under a compressive load. Variation of the Bulk Modulus

For a specific set of conditions (ie. salinity, temperature, and swelling period), the plot of pressure versus volumetric strain is almost linear, except for a small portion of initial strain (Fig. 12). This makes it easy to determine the value of the bulk modulus for one set of conditions. Over the full swelling period of 30 days however, there were some notable fluctuations in the variation of K-value (Fig. 20). There was a sharp initial decrease, then a small increase, followed by a more gradual decrease to almost a constant value at the 


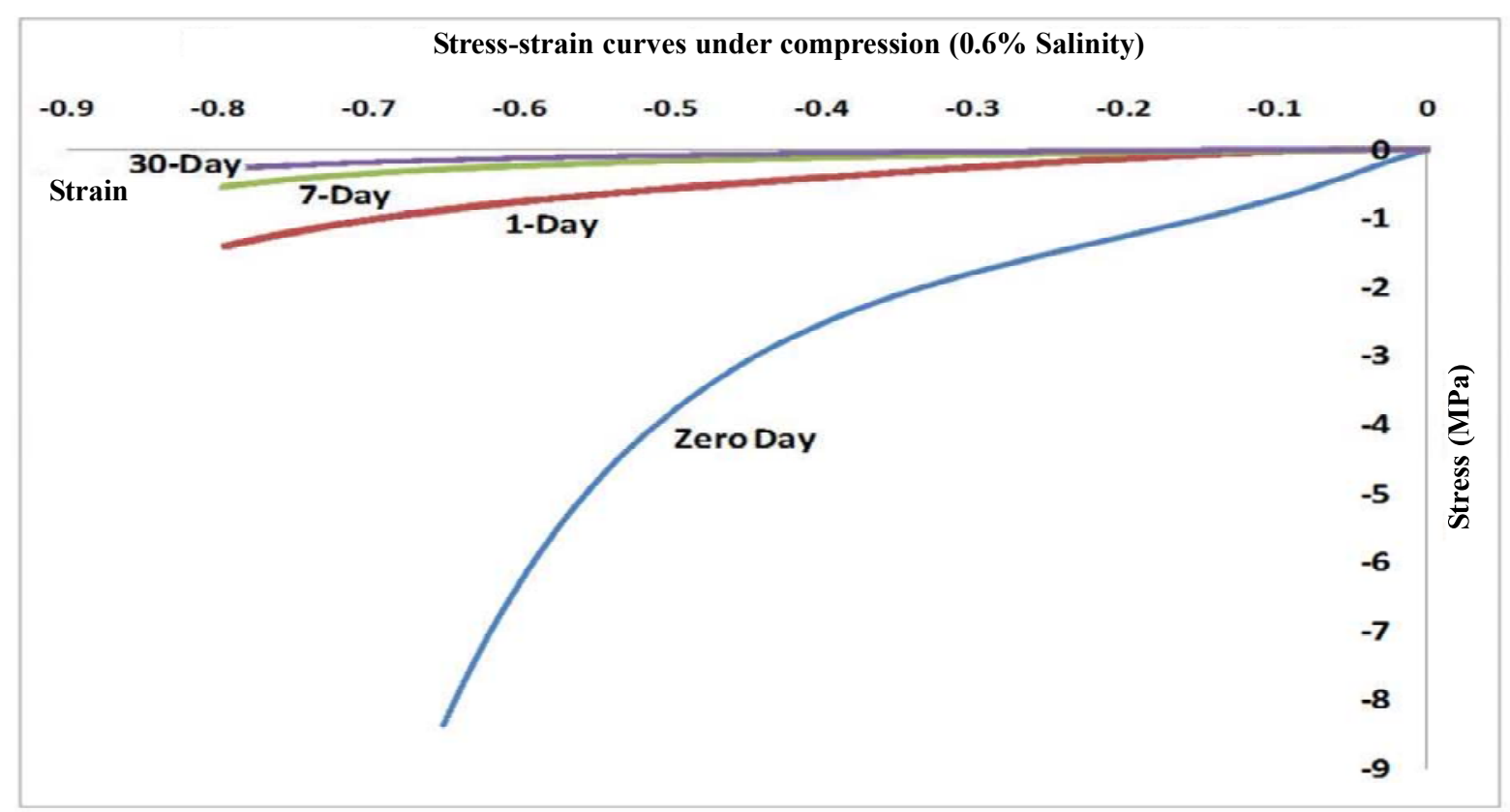

Figure 15. Stress-strain behavior under compression at $0.6 \%$ salinity after various swelling periods (zero, one, 7 and 30 days)

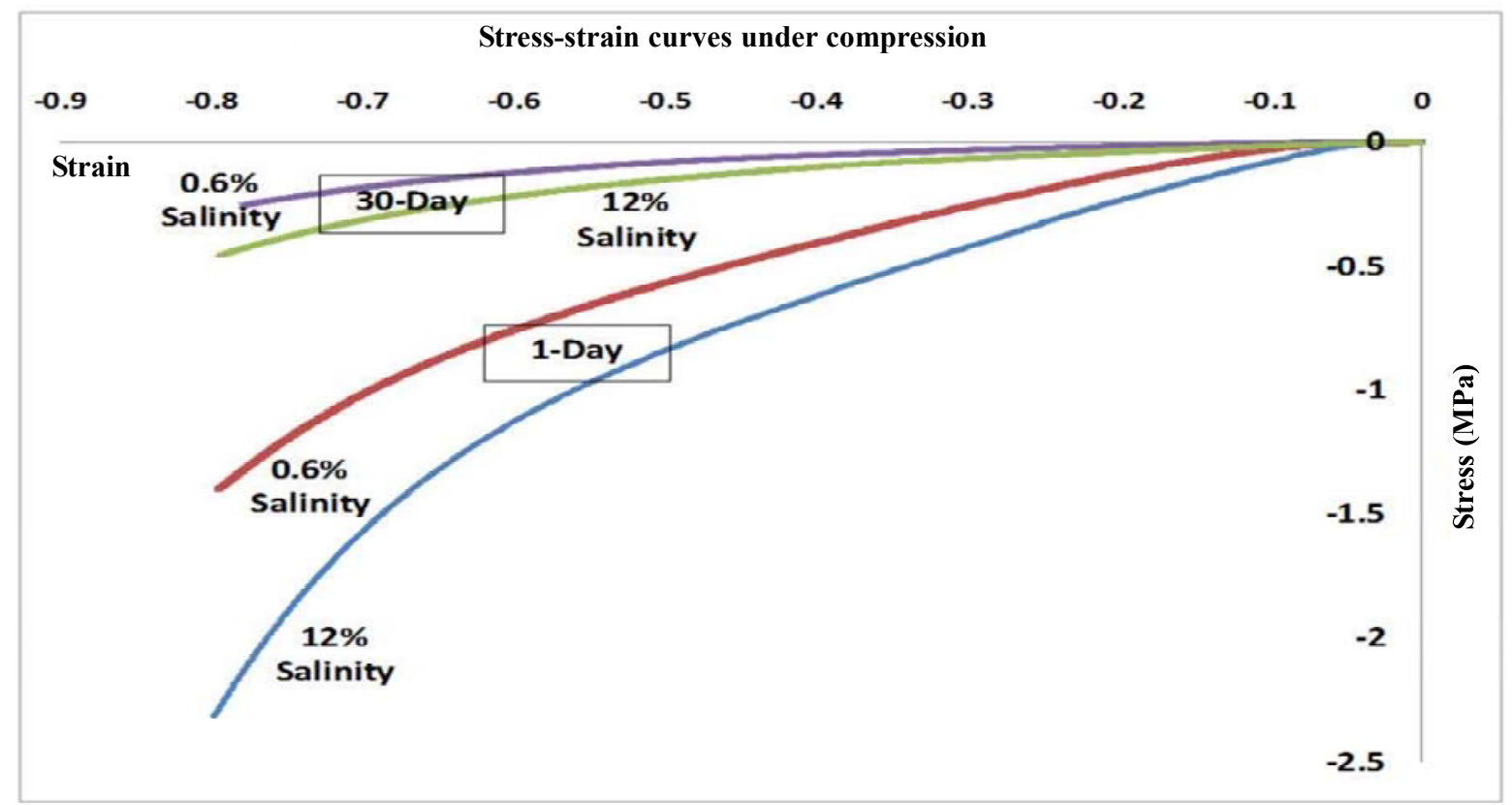

Figure 16. Stress-strain curves under compression for two salinities after one and 30 days of swelling

end of the one-month swelling period for both salinities. Reasons for fluctuation in mechanical behavior of swelling elastomers were discussed above. Specifically for the bulk modulus, there may be another reason as well. In the compression test, pressure was applied to the disc sample only in the axial direction, but it was free to expand in the transverse direction. In the bulk test, on the other hand, the disc specimen was confined in the radial direction by a cylinder; this allows only a uniaxial compression with no transverse expansion. The elastomer was thus forcibly behaving in an incompressible manner in the bulk test as com- pared to in a compressible manner during the compression test. This forced change to incompressible behavior may also have led to irregular trends, including the observed fluctuation.

\section{Conclusions}

In this study, experimental investigations of changes in geometric, hardness, tensile, compressive, and bulk behavior of a water-swelling elastomer were carried out. Thickness and volume changes due to 


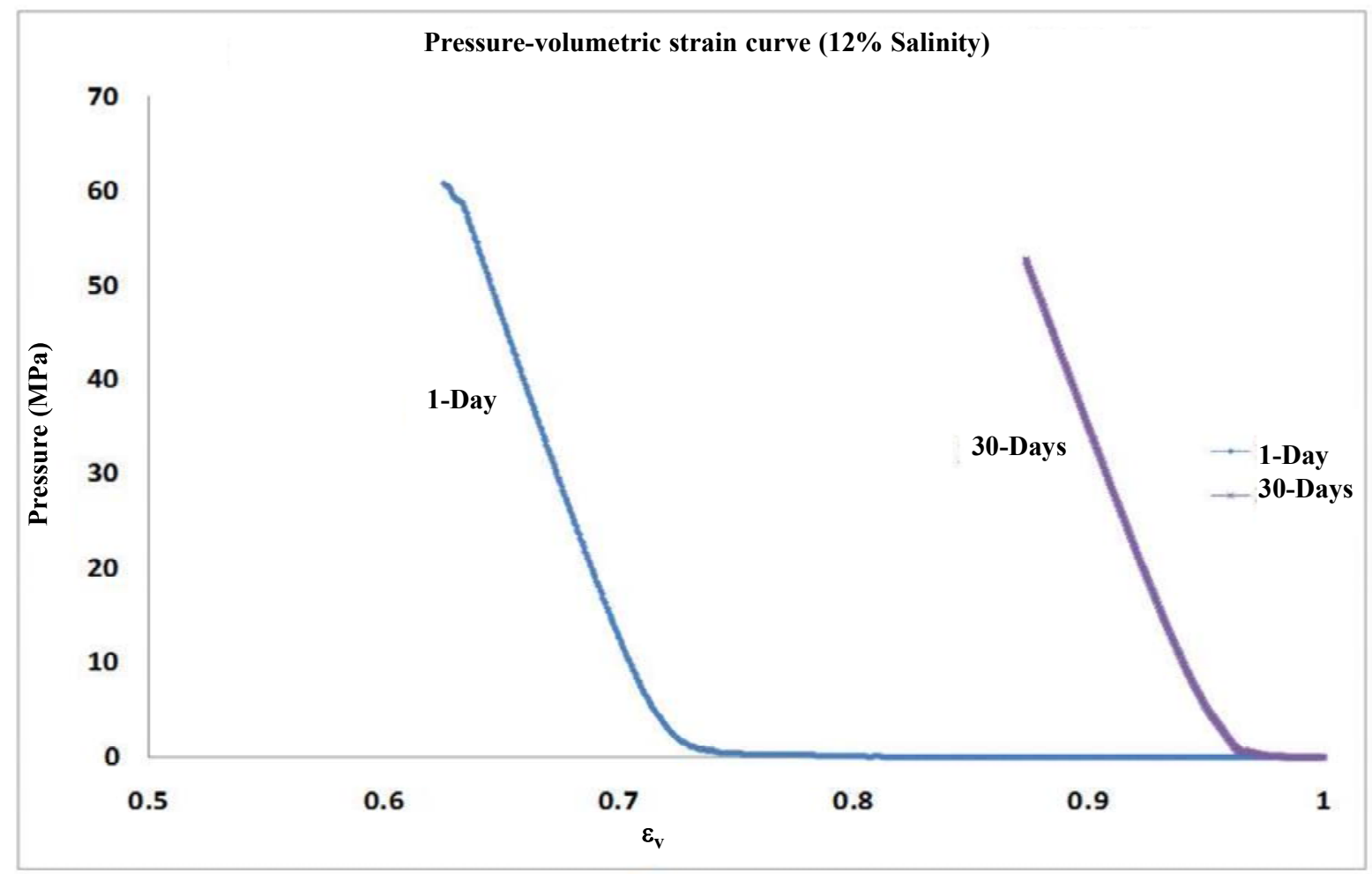

Figure 17. Pressure-volumetric strain curves after one and 30 days of swelling at $12 \%$ salinity

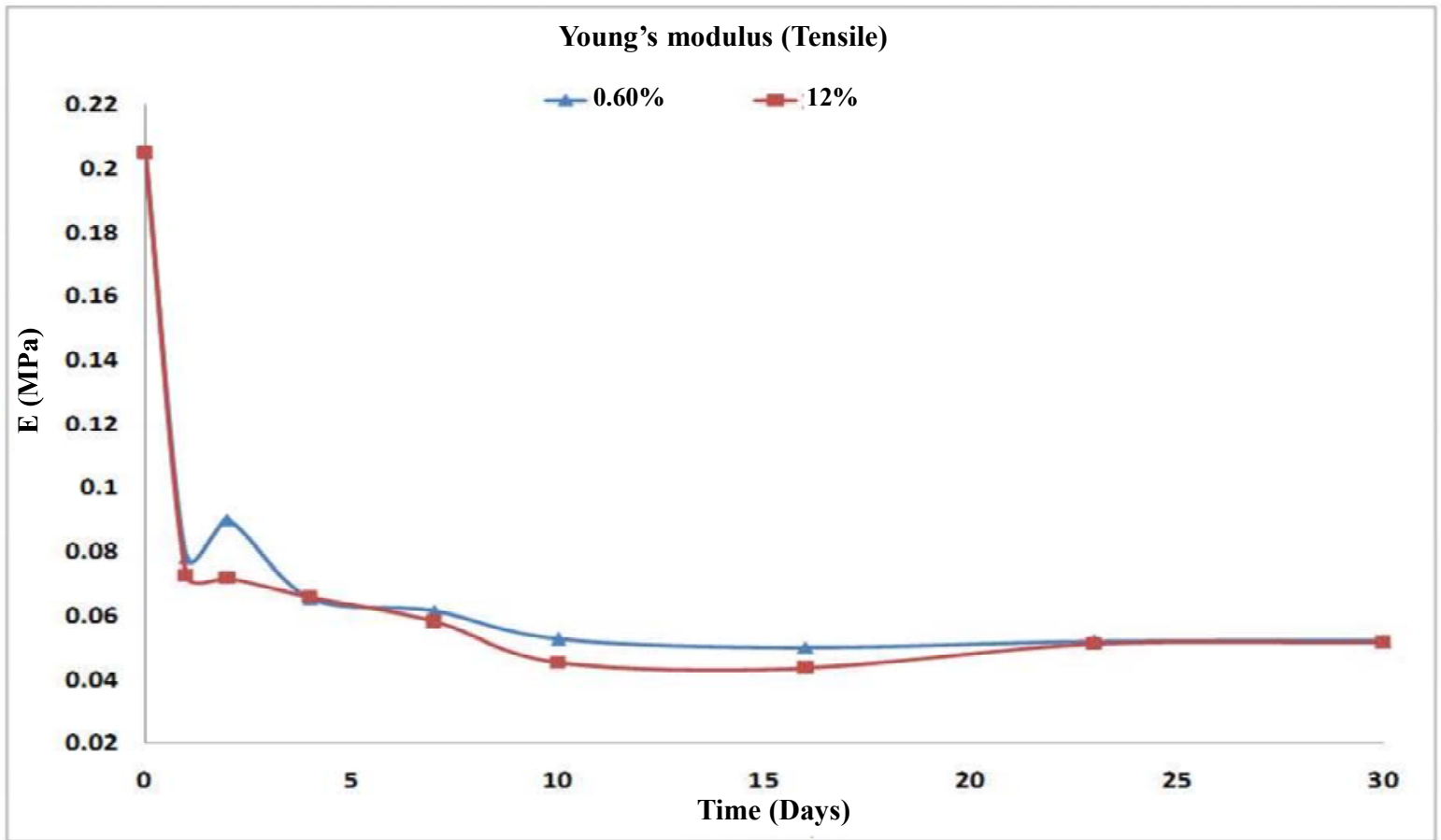

Figure 18. Young's modulus under tension for two salinities for the full 30-day test period

swelling for both salinity levels were more rapid in the first week, displaying an almost $60 \%$ increase, and then was more gradual for the remaining swelling period. Major changes in hardness, density, and mechanical properties were observed within the first two days of swelling at both salinity levels. These initial significant changes were in agreement with the fast-swell nature of the elastomer. The elastic modulus dropped by almost $90 \%$ of its original value in the first few days. Overall, the bulk modulus decreased with 


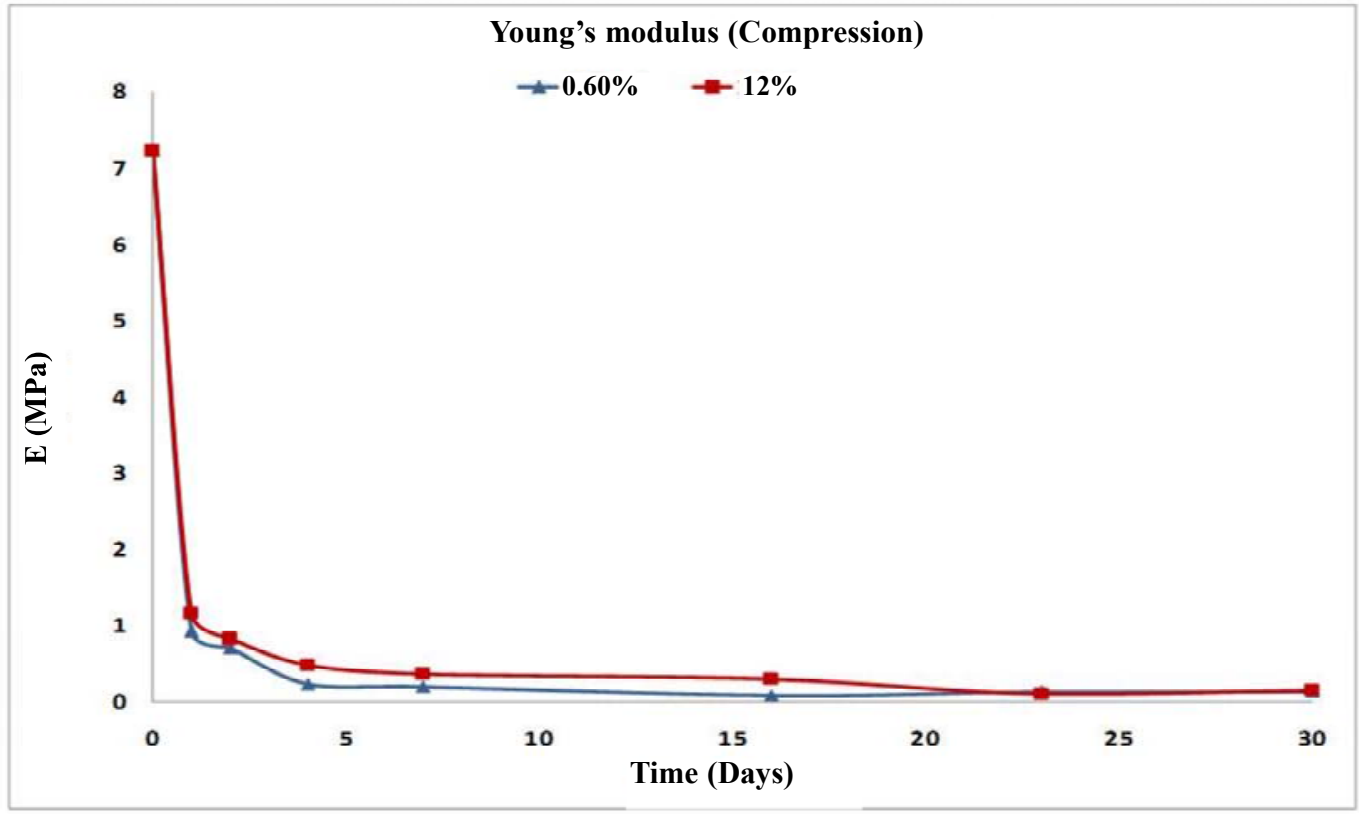

Figure 19. Young's modulus under compression for two salinities for the full 30 -day test period

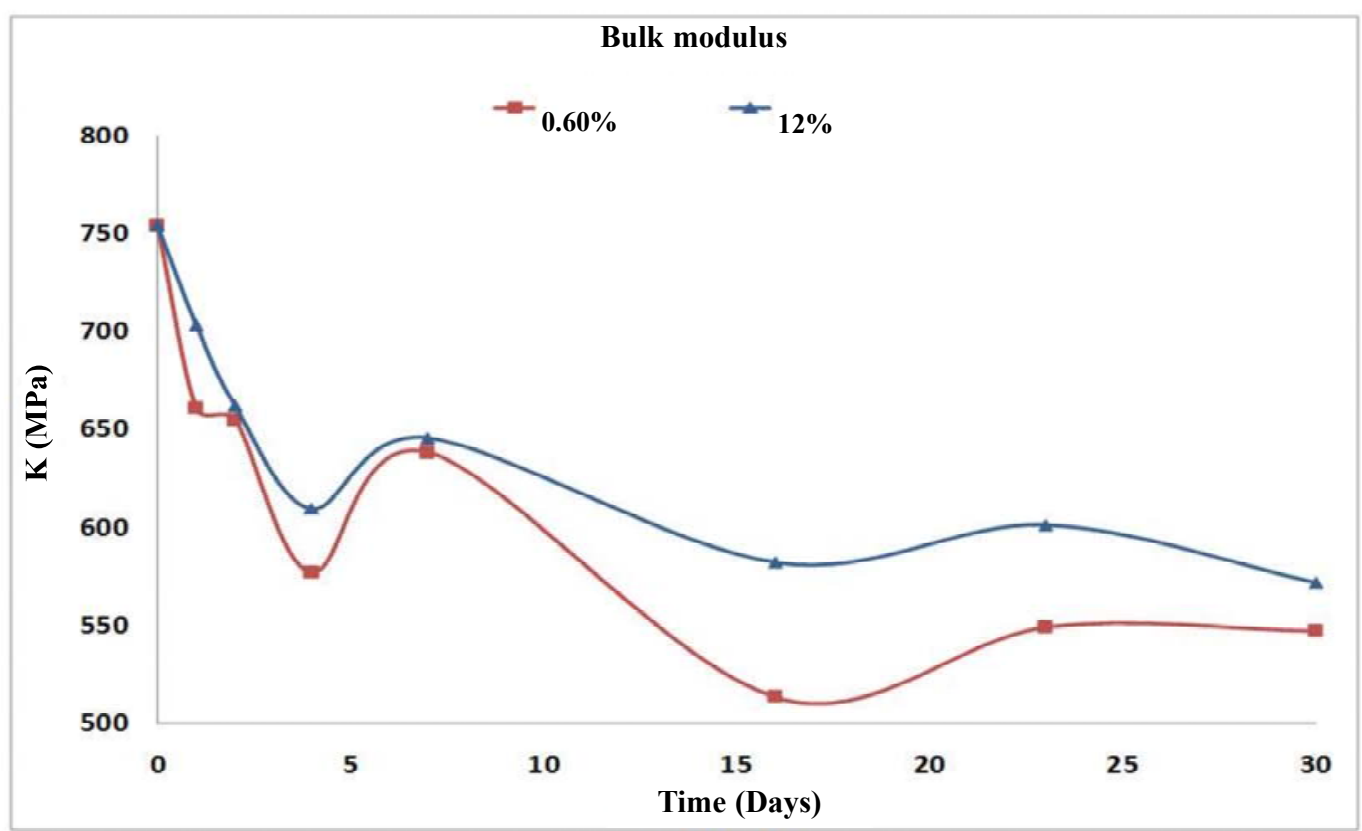

Figure 20. Bulk modulus for both salinities for the full 30-day test period

swelling, but in a somewhat fluctuating manner. Salinity had very little effect on mechanical behavior after the first week. A two-way transport of salt, and the breaking-reforming of cross-link chains in the elastomer was the major cause of these fluctuations.

Insight into the swelling and material behavior could be useful for field engineers in the oil and gas industry in the selection of a suitable swelling elastomer for a particular set of well conditions. The results could also be used by application engineers in improving the design of swell packers and other elastomer seals. Researchers could use this information in the modeling and simulation of elastomer seals.

\section{References}

Akhtar M, Qamar SZ, Pervez T, Khan R, Al-Kharusi MSM (2012), Elastomer seals in cold expansion of petroleum tubulars: Comparison of material models. Materials and Manufacturing Processes 27(7):715-720.

Al-Douseri KMM, Barnes C, Young D, Smith PE (2010), Swellable packers provide a brown field water management solution in open and cased hole. SPE Paper \# 124394-MS, SPE Oil and Gas India Conference and Exhibition (OGIC), Mumbai, India. 
Allison D, Folds D, Harless D, Howell M, Vargus G (2009), Optimizing openhole completion techniques for horizontal foam-drilled wells. SPE Paper \# 125642-MS, SPE Eastern regional Meeting, 23-25 September, Charleston, West Virginia, USA.

Al-Mahrooqi MA, Marketz F, Hinai G (2007), Improved well and reservoir management in horizontal wells using swelling elastomers. SPE Paper \# 107882-MS, SPE Annual Technical Conference and Exhibition. Anaheim, California, USA.

Al-Saiid KA, Abdalla E, Cherif M, Elliot SP (2007), Practical uses of swellable packer technology to reduce water cut: Case Studies from the Middle East and other areas. SPE Paper \# 108613-MS, Offshore Europe, Aberdeen, Scotland, UK.

Al-Yami A, Hisham AN, Al-Saleh HS, Al-Humaidi SA, Al-Arfaj MK, Khalid M (2008), Lab investigation of oil swelling elastomers for smart well. SPE Paper \# 19403-MS, Offshore Technology Conference, 5-8 May, Houston, Texas, USA.

Al-Yami AS, Nasr-El-Din HA, Al-Humaidi AS (2008), Investigation of water-swelling elastomers: advantages, limitations, and recommendations. SPE Paper \# 114812-MS, SPE Asia Pacific Oil and Gas Conference and Exhibition, 20-22 October, Perth, Australia.

ASTM D575-91 (2007), Standard test methods for rubber properties in compression. American Society for Testing and Materials.

ASTM D412-98a. (1998), Standard test methods for vulcanized rubber and thermoplastic elastomers tension. American Society for Testing and Materials.

Cooper KN, McVey A, Schafer D, Cox JD, Hilleary N, Parker D, Crooks J (2008), Completion of a horizontal well with swellable packers to control water production. SPE PAPER \# 116263-MS, SPE Annual Technical Conference and Exhibition, 2124 September, Denver, Colorado, USA.

Ertekin A, Sridhar N (2009), Performance of elastomeric materials in gasoline-ethanol blends - A
Review. SPE Paper \# 09533, Corrosion 2009, 2226 March, Atlanta, Georgia, USA.

Gent AN (2012), Engineering with rubbers: How to design rubber components. Carl Hanser Verlag Publishers: Munich, Germany.

Kubena E, Ross KC, Pugh T, Huycke J (1991), Performance characteristics of drilling equipment elastomers evaluated in various drilling fluids. SPE Paper \# 21960-MS, SPE/IADC Drilling Conference, 11-14 March, Amsterdam, The Netherlands.

Nylund J, Sarah BF, Kristaq M (2010), Power of design: Solid expandable installation sets multiple new records in deepshelf HP/HT Well. IADC/SPE Paper \#128366-MS, IADC/SPE Drilling Conference and Exhibition, New Orleans, Louisiana, USA.

Pervez T, Qamar SZ, Van de Velden M (2012), Comparison between fresh and exposed swelling elastomer. Journal of Elastomers and Plastics 44:237-250.

Qamar SZ, Al-Hiddabi SA, Pervez T, Marketz F (2009), Mechanical testing and characterization of a swelling elastomer. Journal of Elastomers and Plastics 41(5):415-431.

Qamar SZ, Pervez T, Akhtar M, Al-Kharusi MSM (2012), Design and manufacture of swell packers: Influence of material behavior. Materials and Manufacturing Processes 27(7):721-726.

Qamar SZ, Akhtar M, Pervez T, Al-Kharusi MSM (2012), Mechanical and structural behavior of a swelling elastomer under compressive loading. Materials and Design 45:487-496.

Rogers H, Allison D, Webb E (2008), New equipment designs enable swellable technology in cementless completions. IADC/SPE Paper \# 112302, IADC/SPE Drilling Conference Florida, USA.

Tejas K, Ram A, Kumar SA, Raj SR, Badwaik DZ (2009), Swellable packers in unique horizontal completions solves difficult challenges in offshore India vasai east field. SPE Paper \# 124385-MS, Offshore Europe. Aberdeen, UK. 